\title{
The recuperated split cycle - experimental combustion data from a single cylinder test rig
}

\author{
Author, co-author (Do NOT enter this information. It will be pulled from participant tab in \\ MyTechZone) \\ Affiliation (Do NOT enter this information. It will be pulled from participant tab in MyTechZone)
}

\begin{abstract}
The conventional Diesel cycles engine is now approaching the practical limits of efficiency. The recuperated split cycle engine is an alternative cycle with the potential to achieve higher efficiencies than could be achieved using a conventional engine cycle. In a split cycle engine, the compression and combustion strokes are performed in separate chambers. This enables direct cooling of the compression cylinder reducing compression work, intra cycle heat recovery and low heat rejection expansion. Previously reported analysis has shown that brake efficiencies approaching $60 \%$ are attainable, representing a $33 \%$ improvement over current advanced heavy duty diesel engine. However, the achievement of complete, stable, compression ignited combustion has remained elusive to date. The challenge is to induct hot high pressure charge air close to top dead centre into the combustion cylinder and then inject and burn the fuel before the piston has travelled significantly down the expansion stroke. In this paper, we report results from a single cylinder split cycle combustion research engine. Stable, rapid combustion was achieved at $800 \mathrm{rpm}$ and 1200 $\mathrm{rpm}$ at the retarded timings required for a split cycle engine. The calculated rate of heat release was more rapid than typically observed on conventional compression ignition engine suggesting good mixing of the fuel and air during induction. One dimensional cycle analysis was used to calculate the implications of the test results on the full engine cycle which indicated class leading brake efficiencies approaching and possibly exceeding, $60 \%$ are possible from a split cycle engine.
\end{abstract}

\section{Introduction}

Long range - high load factor applications such as long haul freight transportation present a challenge in delivering a low carbon transport system. Light duty vehicles predominantly operate under transient, stop/start conditions over short journeys where the total energy required to reach the destination is within the practical limits of battery technologies. However, heavy duty powertrains commonly operate at much higher loads for longer periods of time. The storage of sufficient electrical energy in a battery for such missions and delivery of a practical re-charging solution would require technological breakthroughs that are currently not projected from fundamental

Page 1 of 10 research in the field. Significant benefits through vehicle and system measures, such as kinetic energy recovery and improved aerodynamics are expected to deliver substantial improvements but the primary source of loss in the system, the prime mover, is more challenging. Reductions in powertrain friction and improvements in combustion efficiency are likely to deliver brake efficiencies as high as 50\% from conventional compression ignition technologies [1]. The addition of waste heat recovery will also drive performance beyond $50 \%$, but there is a broad consensus that brake efficiencies in the range of 50-55\% represents the technology limit from an advanced compression ignition propulsion system with waste heat recovery.

To achieve higher efficiencies, new thermodynamic cycle concepts beyond the Diesel cycle are needed and have been highlighted by several roadmaps, such as those published by the UK Autocouncil [2]. Advanced, low heat rejection combustion systems such as Reactivity Controlled Compression Ignition (RCCI) [3] and alternative engine cycles, such as the double expansion cycle [4] and opposed piston cycles [5] have been suggested, but the authors review of the literature suggests efficiencies of $55 \%$ are the maximum that can be expected from these concepts. The recuperated split cycle engine was first proposed by Coney [6] and further developed by Jackson [7] and Dong $[8,9]$ as a radical departure from the conventional Otto and Diesel cycles. In the split cycle engine, the combustion and compression processes are separated into different chambers with intracycle waste heat recovery. Direct cooling of the charge air during compression to achieve isothermal compression is the key enabler to intracycle waste heat recovery and the high overall efficiency of the cycle. Several authors have predicted cycle brake efficiencies of over 55\% and as high as $60 \%$ for large scale systems.

Splitting the internal combustion engines cycle into separate cylinders is not new; it was probably first described by Harry Ricardo in the 1908 Dolphin engine. Perhaps the most well-known split cycle concept has been the Scuderi engine [10] which reached an experimental prototype stage and successfully ran as a spark ignited light duty gasoline engine. A substantial project was undertaken in the 2000's by National Power in partnership with Ricardo to develop a $3 \mathrm{MW}$ engine, referred to as the ISOENGINE. Very encouraging results from the compression part of the cycle were reported [11]. However, stable and rapid combustion had not been achieved when the project ended [12]. 
More recently, Ricardo, the University of Brighton and subsequently Hiflux Ltd. have completed several projects developing elements of the recuperated split cycle engine, to the point in which when the technology is ready for integration into a full demonstration engine. The work reported in this paper covers an extensive programme to investigate the air induction and combustion processes in the combustor cylinder of the engine. The paper first describes the recuperated split cycle engine and the challenges presented in achieving efficient combustion. The experimental test facility is then described and results from the test programme presented. Finally, analysis of the combustion data to determine the rate of heat release and the implications of the results on cycle efficiency are presented. The paper concludes with remarks on the implications of the results regarding the potential of the split cycle engine to support the delivery of a high efficiency clean engine, or more accurately; the integration of thermal energy recovery a 'thermal propulsion system' as described by the UK Automotive Council for the low carbon transport systems of the future.

\section{The split cycle engine}

The split cycle engine uses a variant of the recuperated Brayton cycle with two main differences; the compression process is near isothermal and reciprocating compressors and expanders are used rather than the turbomachines more commonly used in gas turbine prime movers. As such, the combustion process is intermittent, enabling higher combustion temperatures to be sustained within material limits which typically cap the efficiency potential of a gas turbine. Referring to Figures 1 and 2 and indicative valve timings presented in table 1, the split cycle can be described as follows:

1-2 Induction of air into the compressor cylinder and isothermal compression.

2-3 Constant pressure heat transfer in a recuperator, recovering exhaust heat.

3-4 Induction into the combustor cylinder, (addition of fuel and heating through combustion.)

4-5 Expansion in the combustion cylinder.

5-6 Exhaust and heat recovery in the recuperator, recovering exhaust energy to the pre-combustion charge air.

The isothermal compression process in stage 1-2 could be achieved in several ways; (a) multi stage compression with intercooling (b) the addition of a non-evaporating heat transfer fluid such as water during the compression stroke, or (c) introduction of an evaporating fluid such as liquid nitrogen directly into the compression cylinder during the compression stroke. In the second option, the fluid is kept in the liquid phase to facilitate separation post compression and enable a closed fluid cycle. A significant mass flow of fluid is required to minimize the temperature rise, typically three times the charge air flow to prevent excessive temperature rise and boiling of the water [11]. Option 3 is particularly interesting as the liquid nitrogen will boil during the compression process and does work on the working fluid. The nitrogen will also act as a diluent and contribute to the control of $\mathrm{NO}_{\mathrm{x}}$ emissions from the engine. This concept was investigated as part of the Cool R and Cryopower Innovate UK projects [13].

\begin{tabular}{|l|l|}
\hline Compressor cylinder inlet & $35^{\circ}$ ATDC to $180^{\circ}$ ATDC \\
\hline Compressor cylinder discharge & $-5^{\circ}$ ATDC to $2^{\circ}$ ATDC \\
\hline Combustion cylinder inlet & $-5^{\circ}$ ATDC to $15^{\circ}$ ATDC \\
\hline Combustion cylinder exhaust & $180^{\circ}$ ATDC to $-40^{\circ}$ ATDC \\
\hline
\end{tabular}

Table 1. Indicative split cycle valve timings

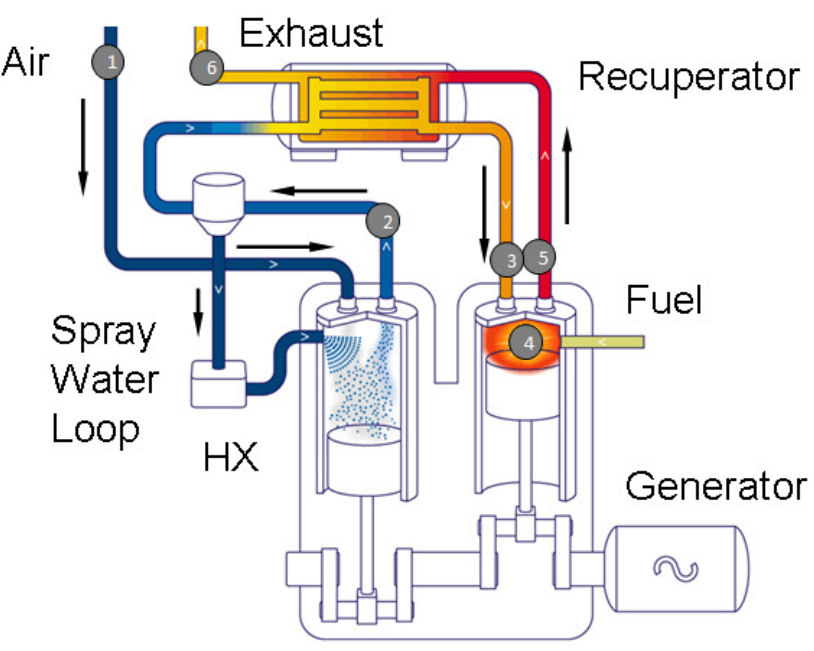

Figure 1. Schematic of the recuperated split cycle engine adapted from [12].

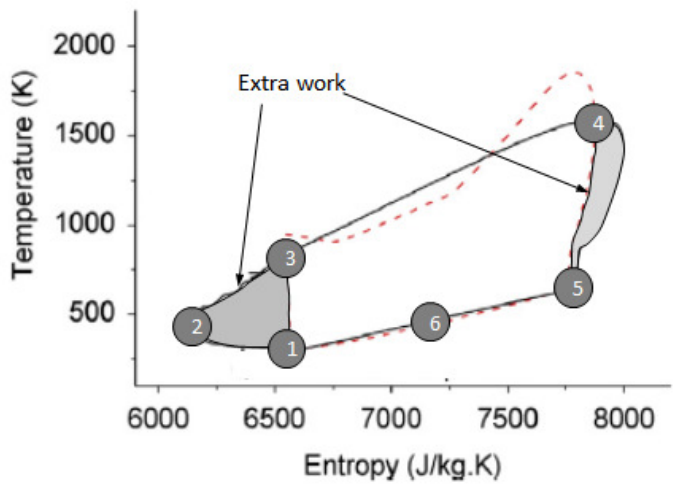

Figure 2. Temperature - Entropy diagram of a conventional diesel engine (red dashed line) and split cycle engines (solid black line) Numbers refer to the positions on the cycle described in Figure 1.

The benefit of isothermal compression can be shown by considering the ideal work of the two processes:

Isothermal Process

$$
W=R T \ln P_{r}
$$

Adiabatic Process

$$
W=\frac{R T}{\gamma-1}\left(P_{r}^{\frac{\gamma-1}{\gamma}}-1\right)
$$


Where $P_{r}$ is the pressure ratio, $T$ the inlet temperature and $R$ the gas constant and $\gamma$ the ratio of specific heats. The potential work saving is therefore proportional to the pressure ratio and at representative diesel compression ratios, savings of over $20 \%$ are possible. But how can the benefits of isothermal compression be integrated into a power cycle? Previous analysis has shown brake efficiencies of more than 55\% [9] and approaching 60\% [6] are possible from the split cycle. Inspection of Figure 2 shows clearly where the savings arise:

- Firstly, the isothermal compression process significantly reduces the work of compression. By recovering exhaust heat, the thermodynamic conditions post recuperator (position 3 in Figure 1) are similar to those at ignition in a conventional diesel engine. The extra 'area' under the T-S diagram (see Figure 2) shows the extra work (for a given fuelling rate) recovered by combining isothermal compression with recuperation. It should be noted that isothermal compression alone will not deliver a substantial improvement in efficiency, as additional fuel must be burnt to achieve equivalent peak temperatures and pressures and hence, work recovery.

- Secondly, the expansion cylinder can operate at near adiabatic conditions and at a different expansion ratio to the compression cylinder compression ratio in a split cycle engine, without the pumping losses incurred in an Otto or Diesel cycle engine [14]. This is because the charge air is introduced at high temperature and pressure close to TDC to the combustion cylinder, therefore the combustion cylinder can be operated with a high chamber wall temperature without the normal penalty in volumetric efficiency observed on conventional engines through charge heating. The high wall temperature reduces heat losses and increases expansion work recovery. The reduction of heat loss combined with the higher expansion ratio results in more expansion work being recovered, further enhancing efficiency.

The relative contributions of the above factors in delivering a brake efficiency of over $50 \%$ were quantified by Dong [9]. The analysis assumed non-evaporative water cooling of the isothermal compressor and the findings are summarised below:

1. Separating the compression and combustion strokes into different cylinders and isothermal compression $-10 \%$.

2. Exhaust recuperation $-20 \%$ improvement.

3. Low heat loss expansion and compression - expansion ratio optimization $-20 \%$.

However, the realisation of a practical split engine cycle is not without challenges. Concentrating on challenges relating to the combustion cylinder, these can be summarised as:

- Induction of the charge air close to top dead centre, requiring rapid intake valve opening and closure with a short dwell period of about $30^{\circ}$ crank angle.

- Unconventional air motion, with the intake air being choked across the inlet valves and very high in - cylinder air velocities during induction and fuel injection.

- Achieving stable complete combustion with retarded ignition timing (15-20 $0^{\circ}$ ATDC).

- High temperatures in the combustion chamber due to the loss of the charge air cooling observed in conventional engines.
The challenge of the split cycle combustion system can therefore be summarised as: get the air into the chamber in the shortest possible time, mix with the fuel and initiate combustion before the piston begins the expansion stroke.

\section{Experimental test facility}

The experimental programme reported in this paper focused on the demonstration of the basic principles of split cycle combustion. A single cylinder Ricardo Titan engine was modified to replicate the combustion cylinder of a split cycle engine. The facility therefore represented only half the cycle, with the high temperature charge air being supplied by a separate air supply system.

The intake and exhaust valves were controlled using custom high speed electro - hydraulic actuators. Hydraulic control was selected to provide independent valve motion control during this earlier research phase of the project. The system used was a total loss hydraulically driven actuator. A flexible mechanical solution would be expected for a production engine and has been demonstrated in work by Scudari [15]. The cylinder head was modified to include a separate flame deck, with intensive cooling via drillings in areas of high thermal load. A two-piece piston with aluminium lower half and steel shallow open combustion chamber was used to (a) improve the temperature tolerance of the piston and (b) insulate the crown from the ring pack and under crown cooling, thereby reducing heat losses. It should be noted that at the start of the programme, how the fuel would burn in such an unusual combustion system was unknown and so the combustion chamber was not extensively analysed and the design was based on engineering judgement. A photograph of the engine installed on the test bed is shown in Figure 3 and key engine data in table 2.

\begin{tabular}{|l|l|}
\hline Bore & $105 \mathrm{~mm}$ \\
\hline Stroke & $130 \mathrm{~mm}$ \\
\hline Compression Ratio & $16.5: 1$ \\
\hline Cycle & 2 stroke \\
\hline Fuel System & Delphi DFI 1.5 \\
\hline Nozzle Configuration & 8 holes, 156 cone angle \\
\hline Nozzle flow \&100 bar & $800 \mathrm{ml} / \mathrm{min}$ \\
\hline Combustion Chamber & Open shallow bowl \\
\hline Inlet valves & Electro-hydraulic, peak lift of 3 mm (cold) \\
\hline Exhaust valves & Electro- hydraulic, peak lift of $5 \mathrm{~mm}$ (cold) \\
\hline
\end{tabular}

Table 2 Titan Engine Parameters.

A dedicated test facility was built at the University of Brighton. This included a high pressure 70 bar air supply for the combustion air. The cold intake air was heated using a prototype recuperator, supplied by Hiflux - a project partner. An insulated high pressure and temperature transfer pipe was installed between the recuperator and engine. As the charge air is at such high pressure in this engine, the normal volumes required for pulsation damping were not required and the volume between the recuperator and inlet valves was minimised to reduce heat losses. The low pressure hot exhaust flow was simulated using a gas burner to provide hot gas at up to $900{ }^{\circ} \mathrm{C}$. The intake and exhaust systems were comprehensively instrumented 


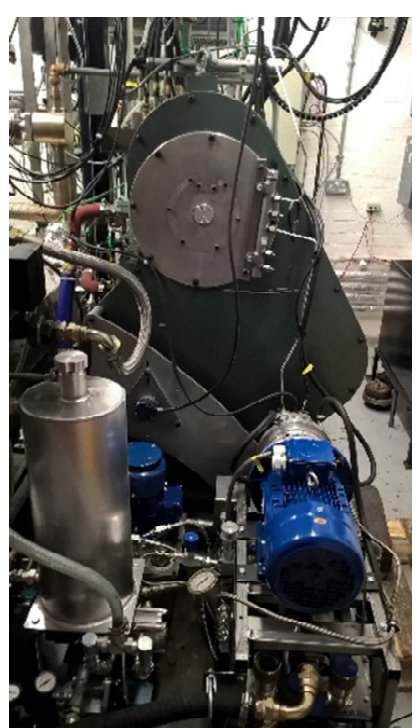

Figure 3. The single cylinder split cycle combustor test facility at University of Brighton.

with pressure, temperature and flow meters. A schematic of the air and exhaust systems are shown in Figure 4. Several parameters were monitored using crank synchronised instrumentation as follows:

- Cylinder pressure

- Fuel injector demand signal

- Intake valve position

- Exhaust valve position

Fuel flow was measured using a AVL733 fuel meter.

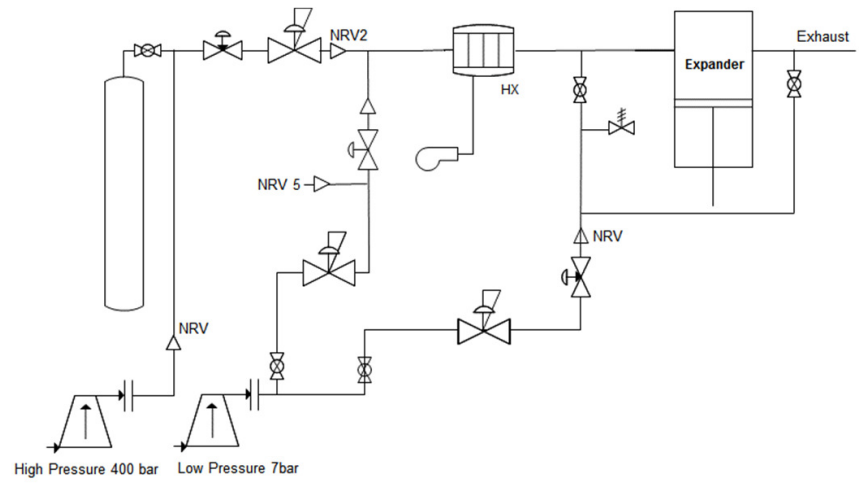

Figure 4. Pipe and instrumentation diagram for the split cycle combustor test facility.

\section{Test programme}

The new facility was successfully commissioned and various subsystems such as the air pre-heating and hydraulic valves characterised. In a split cycle engine, there is a strong relationship between the intake and exhaust conditions of the combustion cylinder and the overall cycle efficiency. The parasitic compression work must be separately accounted for and the overall heat balance across the recuperator checked to ensure sufficient exhaust energy is available for the required charge air heating. The brake load and fuel consumption figures from the single cylinder combustion rig therefore need to be interpreted carefully as the single cylinder only represents part of the engine cycle. The approach taken in the present work was to develop the combustion system to provide validation data for a system model to then optimize and assess the full engine cycle analytically. Due to these complex interactions and practical constraints on the test bed, the intake pressure and temperature, air fuel ratio and injection pressure were treated as independent variables, and set for each sequence of tests. The air flow and brake load would therefore vary as valve and injection timings were changed. This is clearly not the normal way an engine is tested, but was found to offer the most productive method of controlling the engine during the development of the combustion system.

Reference diesel fuel CEC RF06-08-B5, representative of European diesel fuel EN590 was used for the duration of the test programme. During the initial ignition development, the fuel was doped with decane to increase the cetane number to $c .61$ during the initial ignition experiments - but for subsequent experiments, unmodified reference diesel was used with a typical cetane number of $>51$.

\section{Ignition Tests}

As previously mentioned; previous attempts to realize efficient stable split cycle combustion failed. Review of the previous work [12] suggested the combustion chamber was not hot enough to sustain stable combustion during starting. Several starting aids were considered for the present work:

- Intake system pre-heating.

- High power glow plug.

- Improvement in fuel compression ignition propensity through the addition of decane.

- Residual pre-compression.

- Charge air post compression.

The intake system was pre-heated by passing air through the recuperator and through a bypass to short circuit the engine, with the hot side recuperator inlet temperature maintained at $900{ }^{\circ} \mathrm{C}$. This enabled the ducting between the recuperator and inlet port to be heated to $\sim 600{ }^{\circ} \mathrm{C}$ prior to starting the engine. The target temperature was achieved in a matter of minutes due to (a) the insulation and low thermal mass design of the transfer pipe and (b) measures to minimize the length of the pipework.

The engine could not be started using the glow plug on diesel and diesel with the decane additive to increase the cetane number. A range of cranking speeds between 600 and $1000 \mathrm{rpm}$ were tried. It was clear that the charge air was being quenched by the cool combustion chamber walls, resulting in significant cooling of the charge air to below ignition conditions for the fuel. To enable some heating of chamber prior to induction, the exhaust valve closure timing was advanced to trap more residuals in the chamber pre-compression. The subsequent compression of the residuals would then generate a hot gas mixture prior to induction of the fresh charge, in theory pre-heating the combustion chamber walls. Again, the glow plug and high cetane fuel were used to help promote ignition but stable combustion conditions could not be achieved. Some rise in pressure and reduction in motoring torque were observed - but not at a level that could be counted as stable combustion. 
Finally, the valve timings were adjusted to enable the charge to be slightly pre-compressed by advancing the exhaust valve closure to $55^{\circ} \mathrm{ATDC}$ and the inlet valve timing to -40 to $-10^{\circ} \mathrm{ATDC}$. Ignition was readily achieved without the need for the glowplug or high cetane fuel. The advance of the inlet valve closure to before TDC results in a small amount of pre-compression of the hot charge air increasing the trapped charge temperature to above autoignition conditions. This small 'post compression' of the charge negates the quenching of the charge by the cold combustion chamber walls during starting. After a few minutes of running under these conditions to heat up the combustion chamber, the valve timings could be retarded to those required for the split cycle engine. The transition to split cycle valve timings was readily achieved by changing the exhaust, inlet and injection timings in 5 degree increments and could be realty implemented on a production multi cylinder engine.

\section{Test Results at 800 rpm}

At the start of the programme, it was expected the combustion process would be slow at the retarded timings required for the split cycle engine and so initial testing was undertaken at $800 \mathrm{rpm}$. This was to maximize the time for air induction and ignition before the piston had moved significantly down the expansion stroke and potentially slowed or halted the combustion process. After the engine was started, the start of combustion was phased top dead centre (TDC) with an inlet valve period of $20^{\circ}$ (Test T25042016-06). This condition is the closest to 'conventional' diesel combustion that can be achieved on the split cycle engine.

\begin{tabular}{|l|l|l|}
\hline & T25042016-006 & T25042016-013 \\
\hline Torque & $58.8 \mathrm{Nm}$ & $94.3 \mathrm{Nm}$ \\
\hline Inlet Valve opening & $-20^{\circ}$ ATDC & $-10^{\circ}$ ATDC \\
\hline Inlet valve closing & $0^{\circ}$ ATDC & $10^{\circ}$ ATDC \\
\hline Exhaust valve opening & $170^{\circ}$ ATDC & $170^{\circ}$ ATDC \\
\hline Exhaust valve closing & $-58^{\circ}$ ATDC & $-24^{\circ}$ ATDC \\
\hline $\begin{array}{l}\text { Recuperator hot side inlet } \\
\text { temperature }\end{array}$ & $850^{\circ} \mathrm{C}$ & $850^{\circ} \mathrm{C}$ \\
\hline $\begin{array}{l}\text { Inlet } \\
\text { temperature manifold }\end{array}$ & $678^{\circ} \mathrm{C}$ & $690^{\circ} \mathrm{C}$ \\
\hline Inlet manifold pressure & $25.5 \mathrm{bar}$ & $25.5 \mathrm{bar}$ \\
\hline Air mass flow & $38.9 \mathrm{~kg} / \mathrm{s}$ & $49.7 \mathrm{~kg} / \mathrm{s}$ \\
\hline $\begin{array}{l}\text { Start of injection } \\
\text { (electronic) }\end{array}$ & $-9^{\circ} \mathrm{ATDC}$ & $3^{\circ} \mathrm{ATDC}$ \\
\hline Fuel rail pressure & $900 \mathrm{bar}$ & $900 \mathrm{bar}$ \\
\hline
\end{tabular}

Table 3: Summary of $800 \mathrm{rpm}$ test conditions at most advanced (T25042016-006) and most retarded timings (T25042016-013).

The test conditions are summarized in Table 3 and high speed data is shown in Figure 5.

It can be seen that the intake and chamber pressures equalized within the valve opening event and so the maximum amount of air was trapped in the chamber for this valve timing. The oscillations observed on the cylinder pressure trace were also observed in the 1D and CFD analysis of the engine and are therefore thought to be due to reflected pressure waves initiated by the rapid influx of air into the chamber when the intake valves first open.

A small rise in pressure is also evident just before the main rapid pressure rise, which was not observed in the 1D simulation using a simple heat release model. The current theory is that this phenomenon is due to some pre-reactions before the main ignition event, but further testing and analysis is required to develop and verify this hypothesis.

The injection and intake valve timings were then progressively retarded, maintaining the inflection observed on the cylinder pressure where the pressure rises steeply with intake valve closure until combustion became unstable. Results from the most retarded practical timing are also shown in Table 3 and Figure 5 (T25042016-13). It is evident from the drop in cylinder pressure between TDC and $14^{\circ}$ ATDC that the inlet valves were restricting the air flow into the engine towards the end of the induction process and so the combustion chamber was only partially filled. Referring to table 3, more air is trapped in the combustion chamber at the retarded timing, but from the drop in cylinder pressure it is clear more air could be introduced if the valve lift were increased. The initial rate of pressure rise for the two conditions were similar at $12 \mathrm{bar} /{ }^{\circ}$ crank for test 6 and $10 \mathrm{bar} /{ }^{\circ}$ crank for test 13 , despite $14.5^{\circ}$ of injection retard. The combustion chamber volume at the start of combustion - defined as the point where the cylinder pressure starts to rise sharply - will have increased by $30 \%$ between the two tests. It is interesting to note that a similar rate of pressure rise is achieved, despite a substantial increase in the chamber volume and an increase in the rate at which expansion work is removed from the working fluid.

The reason why the combustion system was tolerant to such retarded timings is due to the unusual nature of the air and fuel induction process. During induction, there is a very high pressure difference across the intake valves, resulting in high cross chamber air velocities and into the combustion bowl. In some respects, the air-fuel mixing is more like a homogenous direct injection gasoline engine instead of a conventional diesel engine, in that the air and fuel are added together into the combustion chamber. The air motion will promote very rapid mixing and it is likely that the high initial rate of combustion is due to a significant pre-mixed combustion fraction possibly supplemented by cool flame reaction of the fuel prior to the main ignition event. Kinetic and CFD analysis of the combustion process is in progress to further investigate the exact process.

The interaction of the combustion and intake valve phasing on torque and combustor cylinder specific fuel combustion was studied by varying the valve and injection timings, keeping the start of combustion phased to the point of intake valve closure (Figure 6). The fuel consumption was calculated using the measured fuel flow and brake torque from the single cylinder engine, and so includes friction and pumping losses but not the work required to compress the charge air in the compressor. The exhaust valve closure was also retarded to maintain a constant exhaust valve closure to intake valve opening period. As the timings are retarded, the air flow will increase as more air can be introduced into the combustion chamber due to the increase in volume as the piston starts to move down the expansion stroke. The brake torque also increases as (a) compression work is reduced as the exhaust valve timings are retarded towards TDC, removing any precompression of exhaust residuals and (b) increasing air volume enables more fuel to be injected at constant AFR. The first factor (a) is largely responsible for the substantial improvement in fuel consumption as the timing is retarded.

Page 5 of 10 


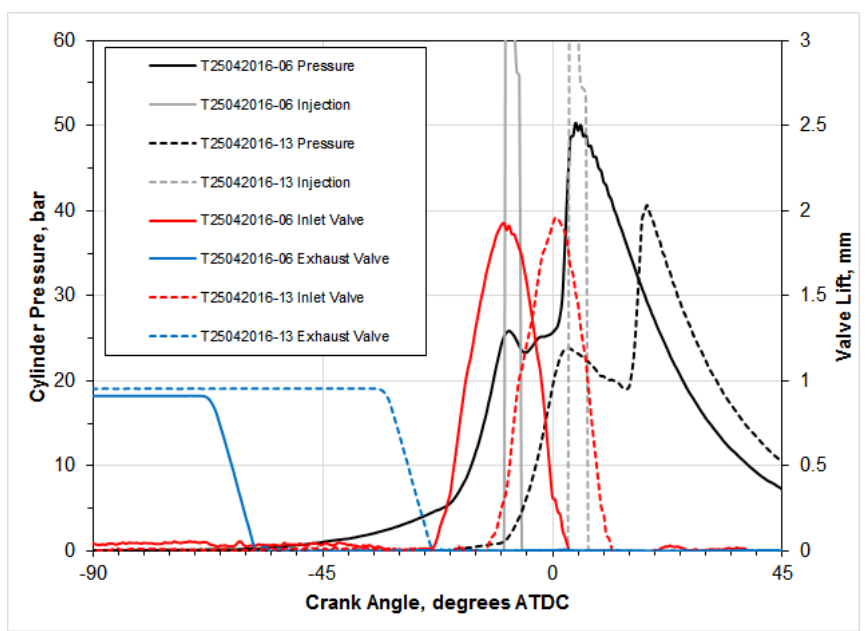

Figure 5. Results at $800 \mathrm{rpm}$ at timings for initial ignition and most retarded injection timing.

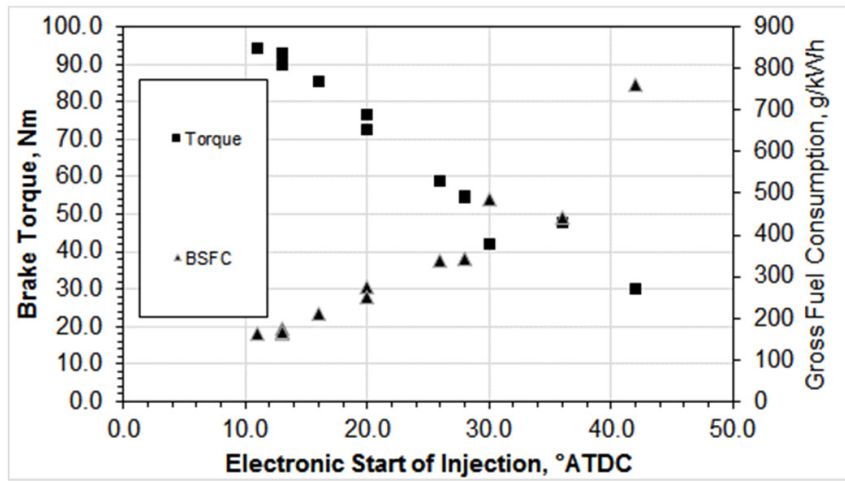

Figure 6. Effect of injection timing on specific fuel consumption at $800 \mathrm{rpm}$.

\section{0 rpm tests}

The engine speed was then increased to $1200 \mathrm{rpm}$, representative of a typical commercial vehicle motorway cruise conditions. Ignition was again achieved (Figure 7) with intake valve closure and start of combustion phased to TDC using the approach previously described. Test conditions and results are summarised in Table 4. At the initial valve and injection timing settings, the rail pressure was varied between 400 bar and 800 bar. Note the injection system was capable of 2000 bar injection pressure but low pressure injection was selected due to the relatively low load and chamber pressure at the conditions investigated, compared to a conventional diesel engine. Higher injection pressures could result in overpenetration and impingement of the fuel on the piston. Previous studies [12] had shown that impingement of the fuel spray on the piston crown contributed to incomplete combustion and some of the problems encountered in previous programmes. However, to achieve the target rate of heat release, it was considered beneficial to (a) promote good mixing and (b) shorten the injection period as much as possible - hence the rationale of increasing the rail pressure. Conversely, the results at 800 rpm indicated pre-mixed combustion was likely to contribute significantly to the combustion process and as a result; low rail pressures may also be beneficial in lengthening the ignition delay and enabling more advanced injection timings.

\begin{tabular}{|l|l|l|}
\hline & T25T14062016-15 & T25T14062016-18 \\
\hline Brake torque & $24 \mathrm{Nm}$ & $21.3 \mathrm{Nm}$ \\
\hline Inlet Valve opening & $-30^{\circ}$ ATDC & $-30^{\circ}$ ATDC \\
\hline Inlet valve closing & $-2.5^{\circ}$ ATDC & $2.5^{\circ}$ ATDC \\
\hline Exhaust valve opening & $180^{\circ}$ ATDC & $180^{\circ}$ ATDC \\
\hline Exhaust valve closing & $-65^{\circ}$ ATDC & $-50^{\circ}$ ATDC \\
\hline $\begin{array}{l}\text { Recuperator hot side inlet } \\
\text { temperature }\end{array}$ & $850^{\circ} \mathrm{C}$ & $850^{\circ} \mathrm{C}$ \\
\hline $\begin{array}{l}\text { Inlet manifold } \\
\text { temperature }\end{array}$ & $29.8 \mathrm{bar}$ & $29.6 \mathrm{bar}$ \\
\hline Inlet manifold pressure & $698^{\circ} \mathrm{C}$ & $696^{\circ} \mathrm{C}$ \\
\hline Air mass flow & $29.5 \mathrm{~kg} / \mathrm{s}$ & $29.9 \mathrm{~kg} / \mathrm{s}$ \\
\hline $\begin{array}{l}\text { Start of injection } \\
\text { (electronic) }\end{array}$ & $-13.5^{\circ} \mathrm{ATDC}$ & $-7.5^{\circ} \mathrm{ATDC}$ \\
\hline \begin{tabular}{l} 
Fuel rail pressure \\
\hline
\end{tabular} & $800 \mathrm{bar}$ & $800 \mathrm{bar}$ \\
\hline
\end{tabular}

Table 4: Summary of $1200 \mathrm{rpm}$ test conditions at most advanced and most retarded timings.

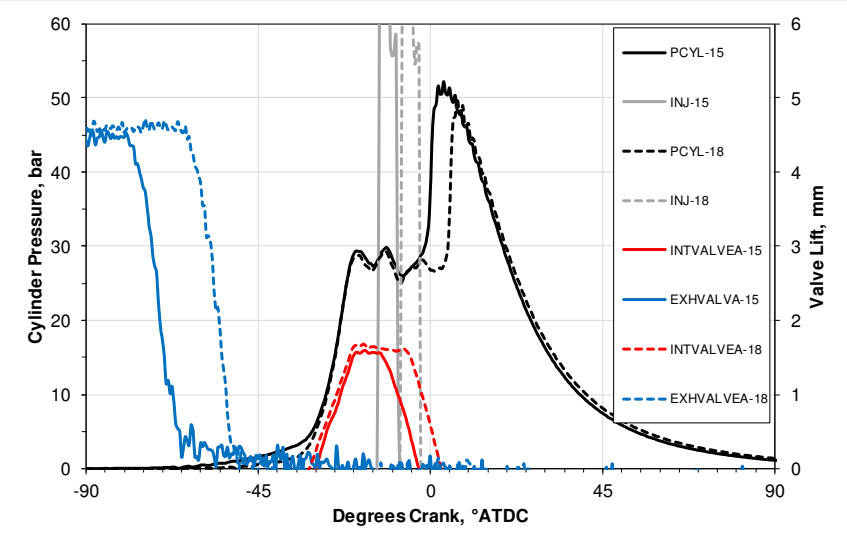

Figure 7. High speed results at $1200 \mathrm{rpm}$ for two injection timings.

The cylinder pressure traces captured from the rail pressure swing are shown in Figure 8. At 400 bar, the injection timing was advanced by $1^{\circ}$ whilst maintaining the same start of combustion timing. Little difference was observed at $600 \mathrm{bar}$ and $800 \mathrm{bar}$, and so $800 \mathrm{bar}$ injection pressure was retained for further testing.

To increase the engine load, the intake valve period was extended relative to the initial opening period, keeping the start of the intake valve opening event constant. This required further retard of the fuel injection timing to prevent ignition whilst the intake valve was open (Figure 7). Similar trends to those observed at the lower engine speeds were seen, with the combustion system being tolerant to ignition retard. At this point, testing was suspended due to failure of a valve guide seal. 


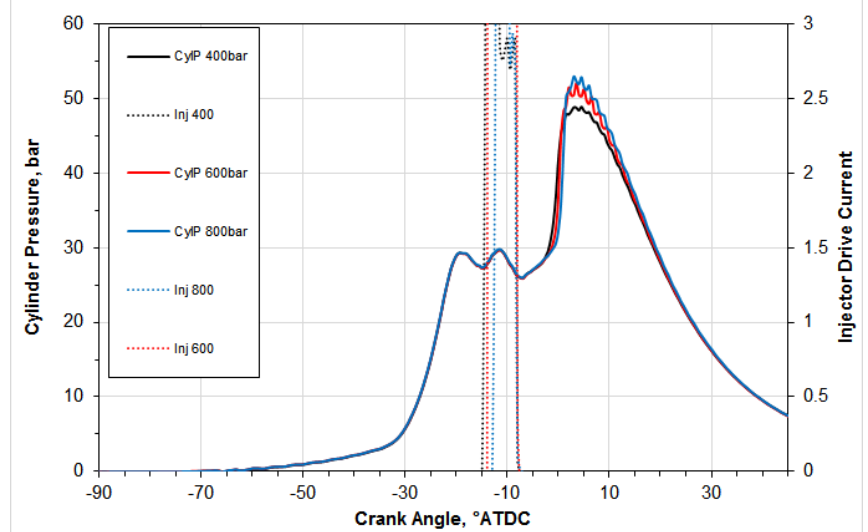

Figure 8. Rail pressure swing at $1200 \mathrm{rpm}$.

\section{Heat release and combustion analysis}

The primary objective of the project was to provide heat release data for validation of a cycle simulation model. Conventional approaches to heat release analysis are invalid because of (a) the fuel in injected whilst the inlet valves are open and (b) it is likely some initial slow reactions occur during the period when the intake valves are open. As such, the closed volume assumption normally made in heat release calculations are invalid. The heat release was instead approximated from the measured cylinder pressure trace by matching the measured pressure to a 1D simulation model of the single cylinder installation. The input heat release rate to the model was adjusted to achieve a good match between the measured and predicted cylinder pressures.

The LMS AMEsim package [16] was used for cycle simulation and the Ricardo WAVE [17] package to analyse heat release. AMEsim was selected due to the software supporting the range of balance of plant components required to model the full split cycle, and WAVE for analysis of the combustion data to exploit the detailed heat transfer models available in the WAVE combustion model. The heat release values derived using WAVE were transferred as an input to the AMEsim cycle model. Details of the modelling approach were reported previously by Dong $[8,9]$.

The AMEsim model includes all the main features of the engine including compression and combustion cylinders, recuperator and transfer pipework. The compressor was assumed to be cooled using a water spray injected into the chamber during the compression stroke, with the water being recovered between the compressor and recuperator. The combustion cylinder was modelling using the IFP combustion model option available in AMEsim. A baseline model of the combustion cylinder was first build to represent a conventional heavy duty diesel engine and validated against published test data. This established the heat release and friction characteristics of the engine. The recupertor model was cross checked against a detailed model of the recuperator built using the Aspen Hysys, which provided more robust analysis of the internal heat transfer processes to ensure the minimum approach temperature limit was maintained along the full length of the recuperator. This was important as the temperature gradient across the heat exchanger is very high and so the temperature profile is non-linear. For the analysis previously reported, the heat release and friction values determined from the conventional diesel engine model were held constant when the model was modified for the split cycle configuration. The approach to friction is simplistic but reasonable as the engine speed and total cylinder displacement (compression plus combustion cylinders) are comparable to a Page 7 of 10 conventional heavy duty engine of equivalent rating. The split cycle engine operates a two stroke cycle but at lower peak pressure and so overall, the friction contribution would be expected to be similar to current diesel engines. For the present work, the heat release model was adjusted to reflect the experimental results.

The calculated normalized heat release rates for the two $1200 \mathrm{rpm}$ cases presented in Figure 5 and Table 3 are shown in Figure 9. The heat release trace is more typical of a gasoline engine than a diesel engine, with a rapid rise in heat release and short combustion period. The load was quite low, at $21 \mathrm{Nm}$, and the injected fuel volume consequently low but the results are encouraging, as the rapid rate of combustion required to deliver high efficiency was achieved.

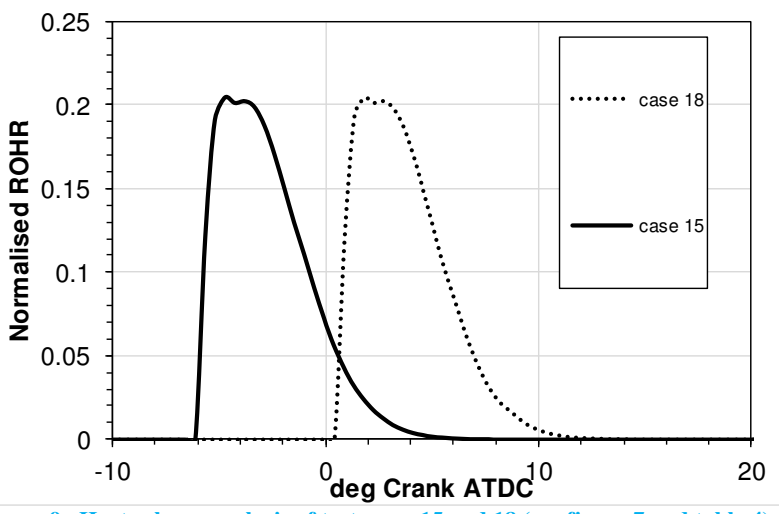

Figure 9. Heat release analysis of test cases 15 and 18 (see figure 7 and table 4).

\section{Discussion}

\section{Combustion Process}

The results from the current programme represent a significant improvement on the previous work on the ISOENGINE, where extended burn periods and difficulties in sustaining stable combustion were observed. Comparing the two programmes, it is evident that the charge air pre-heating system implemented on the present work was more effective as the distance between the recuperator and inlet was much shorter $(400 \mathrm{~mm} v s$ c. $6 \mathrm{~m})$. The ISOENGINE was also fitted with a substantial pulsation damper connecting the three combustor cylinders on that installation. Heat losses would be expected to be substantially higher and the charge temperature was probably too low to achieve sufficiently rapid combustion to sustain the process. The measures taken to start the engine in the present work support this theory, as it was found if the inlet conditions were just insufficient to sustain ignition the engine simply misfires, but once ignition conditions were achieved, the combustion was found to be stable and rapid.

Considering the combustion process, preliminary CFD analysis has shown that the flow across the inlet valves is choked during induction and that high air velocities are formed into the shallow bowl underneath the injector due to the high pressure difference ( $>25$ bar) across the valve at initial valve opening. The resulting air motion would certainly promote rapid mixing of the air and fuel, which is also injected during the air induction process. In particular, high air velocities are likely around the injector tip which are not found in a normal diesel swirl based combustion system. The fuel spray therefore encounters a strong 'cross wind' almost as soon as the fuel leaves the injector nozzle. The fuel will then progressively heat up to the autoignition temperature during the mixing and induction process. It 
is therefore likely that more of the fuel is pre-mixed at the point of ignition than in a modern diesel engine. The high pre-mix fraction would be expected to promote rapid combustion once the ignition conditions are reached. Further testing and analysis is in progress to investigate the split cycle combustion system using the single cylinder engine and CFD.

\section{Implications for Cycle Efficiency}

The AMEsim cycle simulation was used to investigate the impact of combustion period on cycle efficiency. Results of this analysis and comparable analysis on a representative conventional diesel engine are shown in figure 10 based on test results from a single cylinder heavy duty engine operating with a Euro VI calibration [18]. The combustion period was scaled relative to the baseline (scaling factor of 1) established for a conventional Euro VI heavy duty engine. The data in figure 10 essentially shows the effect of burning the fuel more quickly or more slowly than in a conventional diesel combustion system and reflects ideal rather than actual combustion characteristics, and does not reflect changes in the shape of the heat release profile that may result in faster or slower combustion.

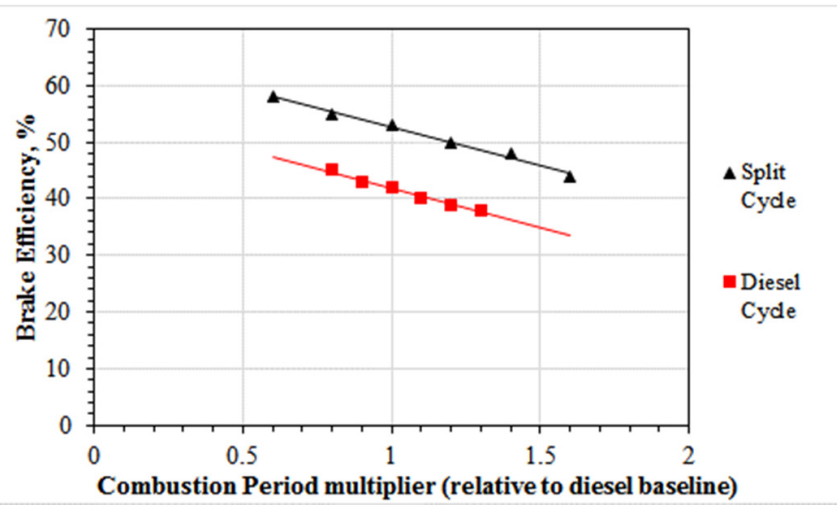

Figure 10. Efficiency-combustion period trade off.

The effect of combustion period on the split cycle efficiency show the same trend as for a conventional diesel engine, but with the line shifted to the higher overall cycle efficiency achieved in the split cycle. Based on the single cylinder results from the present work, the short combustion period delivers a significant efficiency benefit in a split cycle engine, moving the previously reported baseline of $54 \%$ brake efficiency at the best operating point towards $60 \%$. This represents an improvement of $33 \%$ over an advanced heavy duty diesel engine with an efficiency of $45 \%$. Clearly, similar benefit could be achieved on a conventional diesel engine if the combustion period could be reduced, but the split cycle engine offers several advantages in enabling a short combustion period:

- Previous analysis has shown the split cycle engine optimal efficiency is at a lower compression ratio than a conventional diesel engine. Rapid heat release therefore still results in a lower peak cycle pressure than would be required on a conventional diesel platform and so the impact of high rates of heat release on peak firing pressure and therefore structural strength and friction are lower for a split cycle engine than for a conventional diesel engine.

- The combustion process is significantly retarded relative to a conventional engine so the actual rate of pressure rise is lower for an equivalent rate of heat release, reducing combustion noise.
An efficiency walk, comparing a conventional diesel engine, with and without waste heat recovery and a prediction for the split cycle engine is presented in Figure 11, using data from the present work and previous work by Dong [9]. The contribution of the different features of the split cycle engine can be seen relative to potential future conventional engine cycles. The clear benefit of re-engineering the thermodynamics of the internal combustion engine are clear and maintained, even considering the significant improvements that may be achieved using conventional engine technologies. The delivery of an efficiency improvement of this level has a number of benefits [13]:

- Reduced cost of ownership for the vehicle operator.

- Reduced carbon emissions from the transport fleet through the consumption of less fossil based fuel for a given journey.

- $\quad$ Reduced consumption of precious sustainable fuels, derived from bio or synthetic sources.

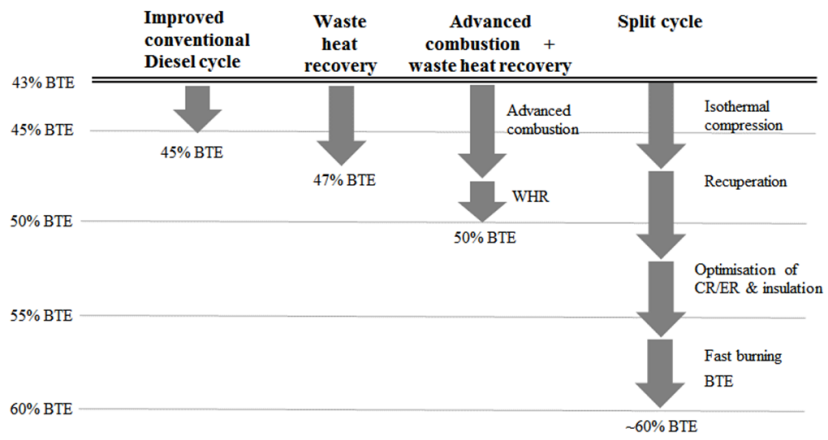

Figure 11. Efficiency walk in terms of Brake Thermal Efficiency (BTE) at the best operating point for conventional and advanced diesel combustion with waste heat recovery (WHR) and predictions for the split cycle engine.

\section{Conclusions and future work}

A single cylinder test rig was successfully built and tested that represents the combustion cylinder of a split cycle engine. From the resulting test and analysis programme, the following conclusions were drawn:

- Ignition was achieved using conventional diesel fuel

- Stable combustion was achieved up to $1200 \mathrm{rpm}$. Further work is required to extend the speed and load range of the engine but early results are encouraging

- Analysis of the measured cylinder pressure profiles indicated that the rate of heat release is higher than typical values seen in conventional diesel combustion systems, even at significantly retarded injection timings

- The high rate of heat release is almost certainly due to strong interaction between the incoming charge air and fuel spray promoting rapid mixing of the air and fuel

- Cycle simulation indicated peak brake efficiencies approaching $60 \%$ are achievable from the split cycle engine using conventional fuels, representing a 33\% improvement over an advanced heavy duty diesel engine.

- The concept has the potential to have significant impact on the cost of ownership, carbon emissions and in the long term, demand for sustainable fuels. 
Future work will focus on:

- Extension of the split cycle combustion system to higher speeds and loads is required to demonstrate the viability of the concept. The present work, although very encouraging, is only over a small part of the engine operating map

- Limited emissions data was gathered during the current programme. More comprehensive measurements and consideration of appropriate emission control strategies to achieve current and future legislative targets are required

- The combustion process is certainly different to conventional gasoline and diesel engines. Further investigations of the combustion mechanics are required, using testing and analytical tools. This work is in progress combining CFD and kinetic modelling tools to investigate further the in - cylinder mechanisms.

\section{Contact Information}

Dr Robert Morgan

University of Brighton

Cockcroft Building

Lewes Road

Brighton BN24GJ

United Kingdom

r.morgan2@brigthon.ac.uk

\section{Acknowledgments}

The work reported in this paper was funded by Innovate UK as part of the Cryopower programme and the EPSRC under grant award EM/M009424/1 Ultra Efficient Engines and Fuels. The authors would like to thank Delphi for the supply of the DFI 1.5 fuel system and subsequent support and LMS for the provision of the AMESim software under their academic support programme. The authors would also like to thank the directors of Ricardo for their permission in publishing this paper.

\section{References}

1. Stanton, D.W., Systematic Development of Highly Efficient and Clean Engines to Meet Future Commercial Vehicle Greenhouse Gas Regulations. SAE Int. J. Engines, 2013. 6(3): p. 1395-1480.

2. Automotive Council UK Roadmap. 2013; Available from: http://www.automotivecouncil.co.uk/2013/09/automotivetechnology-roadmaps/. Accessed 7/6/2017

3. Reitz, R.D. and G. Duraisamy, Review of high efficiency and clean reactivity controlled compression ignition (RCCI) combustion in internal combustion engines. Progress in Energy and Combustion Science, 2015. 46: p. 12-71.

4. Lam, N., Turner, M., Tunestal, P., Andersson, A et al., Double Compression Expansion Engine Concepts: A Path to High Efficiency. SAE Int. J. Engines 8(4):1562-1578, 2015.

5. Abani, N., Nishit, N, Rodrigo, Z. Chiang, M. et al., Developing a 55\% BTE Commercial Heavy-Duty Opposed-Piston Engine without a Waste Heat Recovery System. 2017, SAE Technial Paper 2017-01-0638, 2017

6. Coney, M.W., C. Linnemann, and H.S. Abdallah, A thermodynamic analysis of a novel high efficiency reciprocating internal combustion engine-the isoengine. Energy, 2004. 29(12-15): p. 2585-2600.

Page 9 of 10
7. Jackson N.S., Atkins, A., Ricardo UK Ltd. Split Cycle Reciprocating Piston Engine. US Patent 8,662,060

8. Dong, G., R. Morgan, and M. Heikal, A novel split cycle internal combustion engine with integral waste heat recovery. Applied Energy, 2015. 157: p. 744-753.

9. Dong, G., R.E. Morgan, and M.R. Heikal, Thermodynamic analysis and system design of a novel split cycle engine concept. Energy, 2016. 102: p. 576-585.

10. Phillips, F., et al., Scuderi Split Cycle Research Engine: Overview, Architecture and Operation. SAE Int. J. Engines, 2011. 4(1): p. 450-466.

11. Coney, M.W., Stephenson, P., Malmgren, A. Linnemann, C. Morgan, R.E., Development of a reciprocating compressor using water injection to achieve quasi isothermal compression, in Internaltional compressor engineering conference. 2002, Purdue Uniersity: Purdue.

12. Coney, M.W., Linnemann, C., Sugiura, K, Goto, T., Isoengine data analysis and future design options, in CIMAC Congress. 2004, CIMAC: Kyoto.

13. Jackson N.S., Atkins, A., Morgan R., An altnerative thermodynamic cycle for resiproacting piston engines, in 36th Vienna Motor Symposium. 2015: Vienna.

14. Shabir, F. Authars, M. Ganesan, S. Karthik, R. et al., Low Heat Rejection Engines - Review. 2010, SAE Technical Paper 2010-01-1510, 2010.

15. Meldolesi, R., et al., Scuderi Split Cycle Fast Acting Valvetrain: Architecture and Development. SAE Int. J. Engines, 2011. 4(1): p. 467-481.

16. AMESim. Mentor Graphics.

17. WAVE, Ricardo Softwere

18. Morgan, R., Auld, A., Banks, A. Lenartowicz, C., The benefits of high injection pressure on future heavy duty engine performance, SAE Technical Paper 2015-24-2441, 2015.

\section{Definitions/Abbreviations}

$\begin{array}{ll}\text { ATDC } & \begin{array}{l}\text { Degrees crank after top dead } \\ \text { centre }\end{array} \\ \text { BTE } & \text { Brake Thermal Efficiency } \\ \mathrm{Pr}_{\mathrm{r}} & \text { Pressure ratio } \\ \mathrm{R} & \text { Gas Constant for air } \\ \mathrm{T} & \begin{array}{l}\text { Inlet temperature } \\ \text { compressor }\end{array} \\ \mathrm{TDC} & \text { Top dead centre } \\ \gamma & \text { Ratio of specific heats } \\ \mathrm{W} & \text { Work } \\ \text { WHR } & \text { Waste Heat Recovery }\end{array}$


Page 10 of 10 